\title{
The use of emotional intelligence skills in combating burnout among residency and fellowship program directors
}

\author{
Eiman Khesroh ${ }^{1 *}$, Melissa Butt ${ }^{1,2}$, Annahieta Kalantari ${ }^{3}$, Douglas L. Leslie', Sarah Bronson ${ }^{4}$, Andrea Rigby $^{5}$ and
} Betsy Aumiller ${ }^{1}$

\begin{abstract}
Background: Current rates of burnout among physicians are alarming when compared to nonphysician U.S. workers, and numerous interventions have been introduced to mitigate the issue. However, no interventions have specifically targeted the 30\% burnout rate among physician program directors. The complex and demanding role of program directors necessitates building relationships, solving crises, securing jobs for residents and maintaining well-being of trainees. The aim of this study is to investigate the impact of emotional intelligence (EQ) on burnout levels among program directors.
\end{abstract}

Methods: A cross-sectional survey was administered from May 17 to June 30, 2021 to program directors and assistant/ associate program directors at an academic medical center in south-central Pennsylvania. A self-report questionnaire was used to collect data. The survey included an open-ended question along with the Trait Emotional Intelligence Questionnaire- Short Form (TEIQue-SF), Copenhagen Burnout Inventory (CBI), and demographic questions. All data were analyzed using SAS Version 9.4.

Results: Of the 109 program directors and assistant/associate program directors invited in the survey, 34 (31.20\%) responded. The findings indicate that there is a moderate inverse association between EQ and burnout, suggesting $E Q$ as a protective factor against burnout. We also found that program directors who were considering leaving their position demonstrated higher levels of burnout compared to those who did not. Results from the open-ended question suggest that perceived lack of support, micromanagement, criticism, and extra duties with less payment were among the reasons program directors and associates were considering steeping down from their position. The results showed no association between EQ skills and years of practicing.

Conclusions: Burnout among program directors and assistant/associate program directors is not as alarming as rates of burnout among physicians-in-training. However, despite high level of EQ skills and low burnout level, nearly $43 \%$ of program directors were considering leaving their position. Nurturing EQ skills may be useful in improving retention and reducing turnover among medical leaders.

Keywords: Program directors, Physician burnout, Emotional intelligence, Retention, Turnover

\footnotetext{
*Correspondence: ekhesroh@gmail.com

${ }^{1}$ Department of Public Health Sciences, Penn State College of Medicine, Hershey, PA, USA

Full list of author information is available at the end of the article
}

\section{Background}

The term "burnout", which is defined by the World Health Organization (WHO) as a long-standing workrelated stress [1], is becoming well recognized in the medical field, with incidence rates exceeding those of 
nonphysician U.S. workers (48.8\% vs. $28.4 \%$ in 2014) [2]. Several reports have demonstrated the adverse impact of burnout on physicians' well-being, as well as the risks of increased medical errors (10\%), suicide ideation (6.5\%), alcohol and substance use (10\%), turnover rate (28\%), and reduced physician professional effort (50\%) [3-6]. Additionally, the literature documented on the adverse consequences of burnout include diminished cognitive functions such as impaired attention, memory and executive functions $[7,8]$. Mitigation interventions to reduce burnout have been implemented at both the personal and institutional levels: personal interventions have focused on resilience and mindfulness, while institutional interventions have targeted reducing work hours and overall workloads.

An additional example of an area for personal intervention is emotional intelligence (EQ), which has been defined as the ability to monitor, understand, and guide one's own thinking and actions [9]. EQ skills such as emotional self-awareness, self-control, adaptability, empathy, teamwork, leadership, and social awareness have been cited as essential constructs for individual professional development and decision-making $[9,10]$. Studies have also reported that equipping individuals in a leadership position with EQ skills has had a significant impact, which may not be limited to leader's well-being and retention, but can also improve the entire team's well-being and productivity [11-13]. Consequently, EQ skills are becoming a top priority for institutions seeking maximum productivity and efficiency [11].

The association between burnout and EQ has been studied previously, with most research affirming an inverse association between the two, i.e., higher EQ skills correlate with lower levels of burnout [14, 15]. Despite this, EQ has not been considered a vital component in the medical training of physicians. Burnout is also underresearched among residency and fellowship program directors. A recent study documented that burnout levels in internal medicine program directors reached 29\% and was associated with pronounced levels of turnover as well as created a negative impact on the continuation of teaching and care for residents and patients [16]. Additionally, the authors reported that factors contributing to burnout among physicians in leadership positions included perceived lack of support from department chairs and hospital administrators, lack of training in the leadership role, and poor relationships with colleagues [16]. These contributing factors suggest that it could be helpful to enhance EQ skills among leaders. The aim of the present study is to investigate the impact of program directors' EQ skills on burnout level. We hypothesize that program directors with higher EQ skills experience lower levels of burnout.

\section{Methods}

\section{Aim, design, setting}

The primary objective of the study is to evaluate the association between EQ skills of residency and fellowship program directors, including assistant/associate program directors, and level of burnout. A cross-sectional survey including fellowship and residency program directors and assistant/associate program directors at an academic medical center in south-central Pennsylvania was conducted from May 17, 2021, through June 30, 2021. Recruitment involved obtaining a list of fellowship and residency program directors and assistant/ associate program directors from the director of graduate medical education at the institution and contacting the prospective participants via email. Program leaders were sent a link containing the study's consent material; if they agreed to participate, they were taken to the survey. The survey was administered through REDCap, a secure online web application [17].

\section{Materials}

The survey included two instruments: the Copenhagen Burnout Inventory (CBI) and Trait Emotional Intelligence Questionnaire-Short Form (TEIQue-SF). The CBI is a publicly available and validated burnout instrument with high internal reliability and consists of 19 questions divided into three subcategories: personal-, work-, and colleague-related burnout. Each category is evaluated on two physical and psychological cores: exhaustion and fatigue [18]. Participants responded to each question using a 5-point Likert scale ranging from 1 (always) to 5 (never), with aggregate scores ranging from 0 to 100 . Results were trisected into low, medium, and high scores as per instrument guidelines [19].

The TEIQue-SF is a 30-item validated instrument [20] that provides a global assessment of four scales: wellbeing (WB), self-control (SC), sociability (SOC), and emotionality (EM) [20, 21]. The overall assessment of the WB domain provides an insight into how happy and positive an individual is; the SC domain determines the extent to which an individual is able to cope with external stressors; SOC examines the individual's ability to listen and communicate in a self-assertive manner; and EM evaluates the individual's ability to express and interpret emotions needed to establish and maintain a relationship with others. The TEIQue-SF is scored on a 7-point Likert scale ranging from 1 (completely disagree) to 7 (completely agree). In addition to the CBI and TEIQueSF instruments, the survey included a demographic section where participants provided information regarding their age, gender, and marital status, as well as whether program directors ever considered leaving their position and the leading reasons behind this decision. For those 
who responded that they did have a desire to leave the institution, an additional open-ended question was posed inquiring about if they ever wanted to leave their position as program directors.

A number of studies have highlighted the additional strain that the COVID-19 pandemic placed on medical education at all levels [22, 23]. As this research took place during the COVID-19 pandemic, a single item to measure the leaders' perceived stress resulting from the impact of the COVID-19 pandemic was included in the questionnaire. This item asked the program director to rate their level of agreement that the COVID-19 pandemic adversely impacted their emotional exhaustion level with " 1 " being strongly agree and " 5 " being strongly disagree.

\section{Statistical analysis}

Descriptive statistics were used to characterize the study sample. Means and standard deviations (SD) were used to analyze continuous variables. Frequencies and percentages were used to present any categorical variables. The association between two continuous variables was evaluated using the Pearson Correlation Coefficient (PCC) and 95\% Confidence Limits (CL) and linear regression models. Linear associations between EQ and burnout skills were controlled for by the perceived impact of the COVID-19 pandemic. Associations between continuous and categorical variables were calculated using Spearman Correlation Coefficients (SCC) and 95\%CL along with ANOVA. All data were analyzed using SAS version 9.4 (SAS Institute Inc., Cary, NC).

\section{Results}

Of the 109 program leaders (directors and associates) invited to the study, 34 (31.2\%) elected to participate. Table 1 shows that, out of the 34 respondents, 20 $(58.82 \%)$ were male, and more than half of respondents identified as White $(n=27 ; 79.41 \%)$. The majority of the sample $(n=26 ; 76.47 \%)$ were age 40 or older and were married ( $n=31 ; 91.18 \%)$. Sixteen respondents $(47.06 \%)$ reported having been a program director for less than 5 years, while only $8(23.53 \%)$ had a 10 -year experience as a program director. The remaining participants $(n=10$; $29.41 \%$ ) had been program leaders for 5 to 10 years. Program leaders demonstrated variable levels of burnout, with 22 respondents $(68.75 \%)$ in the low range of burnout and $10(31.26 \%)$ in the moderate to highest range.

Table 2 shows that work-related (mean $=42.97$; $\mathrm{SD}=18.89$ ) burnout was higher than personal- and colleague-related burnout (mean $=40.95 ; \mathrm{SD}=22.04$ and mean $=27.08 ; \mathrm{SD}=21.96$, respectively). Table 2 also shows that program leaders also exhibited a high level of EQ skills across the four subdomains (WB, SC, EM,
Table 1 Demographics $(N=34)$

\begin{tabular}{ll}
\hline & N (\%) \\
\hline Gender & \\
Male & $20(58.82 \%)$ \\
Female & $14(41.18 \%)$ \\
Age & \\
$\quad<40$ years & $8(23.53 \%)$ \\
40+ years & $26(76.47 \%)$ \\
Race & \\
White/ Caucasian & $27(79.41 \%)$ \\
Asian/ Pacific Islander (e.g. Native Hawaiian) & $2(5.88 \%)$ \\
Two or more & $2(5.88 \%)$ \\
Decline to answer & $3(8.82 \%)$ \\
Marital Status & \\
Single/ Widowed & $2(5.88 \%)$ \\
Married/ Significant Other & $32(91.18 \%)$ \\
Tenure Years & \\
$\quad<5$ years & $16(47.06 \%)$ \\
5-10years & $10(29.41 \%)$ \\
$>10 y e a r s$ & $8(23.53 \%)$ \\
Intentions to Leave Leadership position & \\
Yes & $15(42.86 \%)$ \\
No & $20(57.14 \%)$ \\
\hline
\end{tabular}

Table 2 Emotional Intelligence and Burnout Scores among Program Directors

\begin{tabular}{ll}
\hline & $\begin{array}{l}\text { Program Directors } \\
\text { Mean, SD }\end{array}$ \\
\hline EQ Domains & \\
Well-Being & $4.70,0.92$ \\
Self-Control & $4.98,0.91$ \\
Emotionality & $5.30,0.84$ \\
Sociability & $4.72,1.03$ \\
Total & $5.19,0.85$ \\
CBI Domains & \\
Personal & $40.95,18.97$ \\
Work & $42.97,18.89$ \\
Colleague & $27.08,21.96$ \\
Total & $38.17,18.97$ \\
\hline
\end{tabular}

and SOC), with no relation to years of experience. The PCC $(95 \% \mathrm{CL})$ showed a moderate inverse association between burnout and EQ $(-0.51[-0.73,-0.16])$, which suggests EQ may be a protective factor against burnout. These findings suggest that acquiring high EQ skills could result in lower levels of burnout.

In Table 3, we present associations between burnout and years of tenure, desire to leave position, and impact of COVID-19. Burnout levels remained constant along 
Table 3 Associations between burnout and years of tenure, desire to leave position, and impact of COVID-19

\begin{tabular}{|c|c|c|c|c|c|}
\hline Variable & Level & $\mathrm{N}(\%)$ & Mean (SD) & ANOVA $P$-Value & $\begin{array}{l}\text { Spearman } \\
\text { Correlation } \\
\text { Coefficient }(95 \% \mathrm{CL})\end{array}$ \\
\hline \multirow[t]{3}{*}{ Years of Tenure } & $<5$ years & $15(48.34 \%)$ & $39.18(19.08)$ & 0.94 & $-0.06[-0.40,0.31]$ \\
\hline & 5-10years & $9(29.03 \%)$ & $37.30(19.74)$ & & \\
\hline & $>10$ years & $7(22.58 \%)$ & $36.03(21.71)$ & & \\
\hline \multirow[t]{2}{*}{ Considered Leaving } & No & $17(53.13 \%)$ & $27.58(15.78)$ & 0.0003 & $0.66[0.39,0.82]$ \\
\hline & Yes & $15(46.86 \%)$ & $50.17(14.88)$ & & \\
\hline \multirow{2}{*}{$\begin{array}{l}\text { Emotionally Exhausted by } \\
\text { COVID-19 }\end{array}$} & Agree/Neutral & $28(87.50 \%)$ & $40.31(19.15)$ & 0.09 & $0.29[-0.07,0.58]$ \\
\hline & Disagree & $4(12.50 \%)$ & $23.21(8.64)$ & & \\
\hline
\end{tabular}

years of medical practice with a SCC (95\% CL) of -0.05 $(-0.40,0.31)$, suggesting no association between burnout level and the number of years a program director has been practicing medicine $(p$-value $=0.94)$. However, program leaders who indicated an intention to leave their position $(n=15 ; 42.86 \%)$ reported a significantly higher levels of burnout compared to those with no intention of leaving ( $p$-value $=0.0003)$. We also looked at the impact of the COVID-19 pandemic on program leaders and found a positive association between COVID19 and burnout with an SCC (95\% CL) of $0.29(-0.07$, 0.58). Program directors who reported being impacted less by COVID-19 had noticeably lower burnout scores; however, this association was trending towards significance $(p=0.09)$. Figure 1 illustrates the association between EQ and burnout for program leaders and

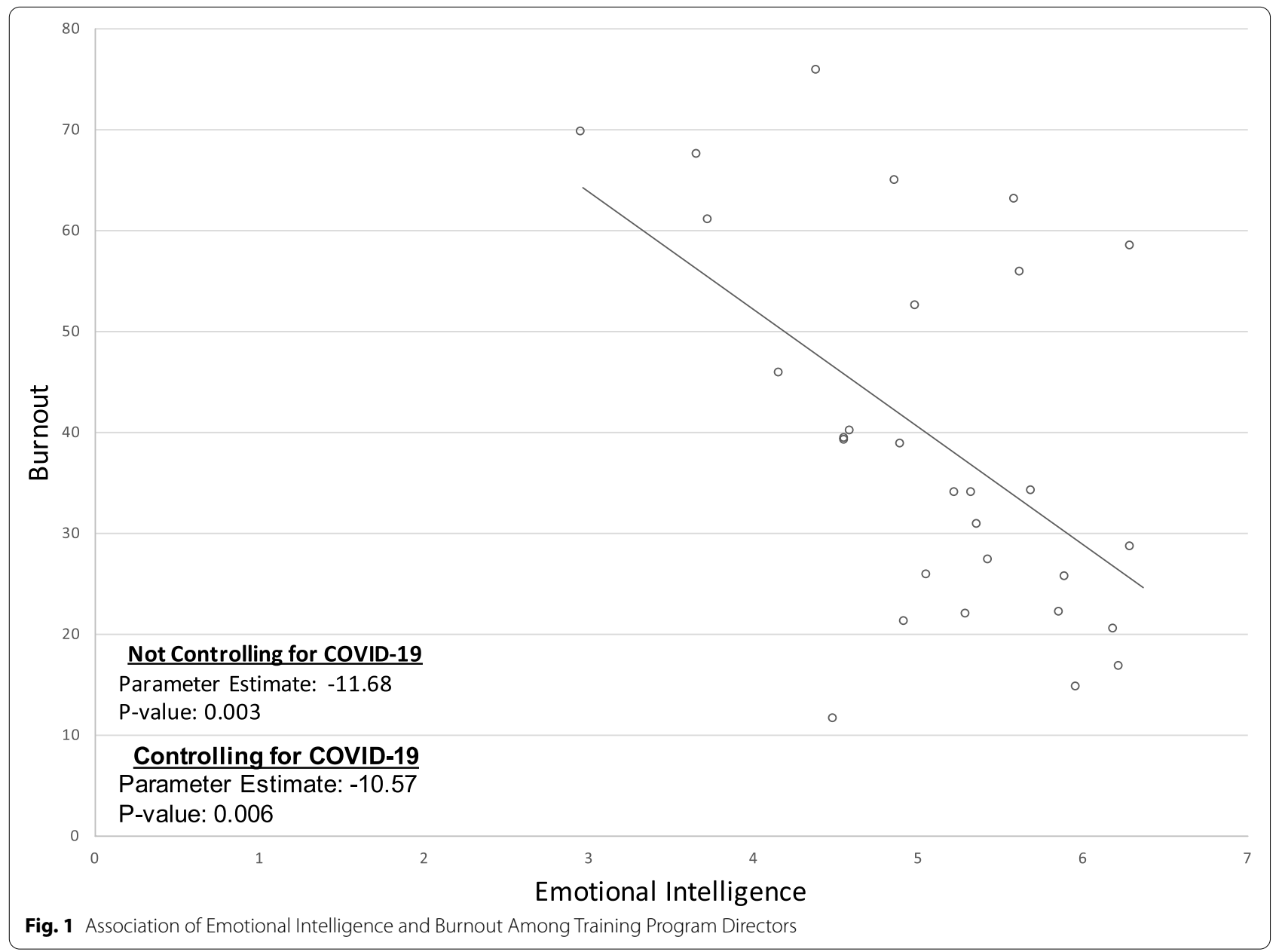


demonstrates that as EQ scores increase, burnout scores decrease $(p=0.003)$. After controlling for the impact of the COVID-19 pandemic, this association remains significant $(p=0.006)$.

An open-ended question was posed to the 15 respondents who stated an intention to leave; of these, 13 indicated that lack of support and micromanagement were the main reasons they were considering a job change. Approximately 15 respondents reported an intention of leaving and $6(46.15 \%)$ out of the 13 respondents who provided a response to the open-ended question indicated that lack of support and micromanagement were the main reasons to considering leaving the position.

\section{Discussion}

The association between burnout and EQ among residents has been frequently investigated $[14,15]$. However, to date there has been little research on burnout levels among program directors. The hypothesis of this studythat possession of high EQ skills is associated with lower levels of burnout-was supported by our data. Physician leaders such as residency and fellowship program directors have responsibilities for program administration and operations; recruitment and selection of residents; education; supervision; assessment, promotion, and disciplinary actions; and for establishing an effective learning climate at all teaching sites. Therefore, directors play an essential role in the department and organization [16, 24]. The complexity of program directors' roles assigned by the Accreditation Council for Graduate Medical Education (ACGME) engendered a burnout level close to $30 \%$, in addition to high turnover rates [16].

The role-specific challenges have been found to be related to frustration with regularity requirements, lack of appreciation and support from the department chair and hospital administration, low satisfaction with colleague relationships, and lack of training in dealing with residents' problems $[16,25]$. These themes related to lack of support and interpersonal challenges were affirmed by some of the respondents in our study; they stated that "micromanagement from direct boss (department chair), conflicting personalities with select colleagues, opinion not respected, generational differences [between] self and learners, little room for additional growth in this role, not enough time given to focus on program/department/ institutional issues related to GME" and "criticism of those around me" were contributing factors to burnout. These sentiments regarding lack of professional support in addition to interpersonal challenges presented in a number of open-ended responses from program leaders and highlight the impact that these particular factors have on the work-related burnout that these leaders experience.
Additionally, the recent abolishment of the protected time for core faculty has left a significant number of physicians, notably assistant program directors who are engaged in medical education and research, to feel unrewarded as one respondent stated that having "more work and no increase in pay" to be emotionally draining [26]. These factors suggest the need for further investigation by academic institutions, as well as the ACGME. Physician-leaders in our study who were considering leaving their position cited micromanagement by superiors, lack of departmental and institutional support, and continuous criticism. Some said that burnout stems in part from feeling "fatigued, less invested in program" and "challenges of always innovating," which is consistent with previous research [25].

Being skillful with EQ prepares individuals in leadership positions to delegate, manage conflicts, and build relationships. However, despite the reported high emotional intelligence scores in this study across the four subdomains (WB, SC, SOC, and EM), the data suggest a discrepancy in communication and misalignment in relationships with administrators, physicians-in-training, and colleagues in terms of sharing opinions, respecting one another, and dealing with opposite personalities. To excel at the use of EQ skills, one should be adaptive to using these skills intra- and interpersonally, i.e., helping oneself and others, respectively [27]. One of the four building blocks of $\mathrm{EQ}$ demands that the individual has "the ability to accurately perceive your own and others' emotions; to understand the signals that emotions send about relationships; and to manage your own and others' emotions" [28]. However, when an individual is burned out or emotionally exhausted, the emotionally guided behaviors and thinking become distorted [27]. Thought distortion was noted in several studies that investigated the influence burnout has on cognitive and executive functions $[7,8]$. Memory, attention, flexibility in switching tasks and hence professional performance were found to be impacted [7]. The result is a cycle of unresolved problems among individuals lacking EQ skills.

Program directors are in a position of leading teams, building relationships, influencing careers, and maintaining the well-being of others. They are expected to overcome crises, motivate different personalities, and achieve effective communication for optimal outcomes among the learners. In order to ensure that these responsibilities are delivered suitably while securing program directors' well-being, the ACGME in addition to the institution should be providing solutions to the factors leading program directors to feel emotionally exhausted. The solution begins with ensuring a positive emotional culture at the institutional level that provides healthy support and appreciation. In addition, if improving the EQ skills at 
the personal level is found promising to boost the wellbeing and productivity of program directors, then EQ skills should be administered to all healthcare providers working in that institution to ensure successful interpersonal skills. The role of program directors should not lead to feeling a need "to pursue other endeavors" or "have thought about leaving my job in general," as reflected by some respondents, when the solution resides in including program directors in the process of building institutional cultural and emotional competencies.

There are some limitations to this study. First, the sample size is small. Consequently, these results may be impacted by response bias. We tried to increase the number of participants by inviting program directors from all departments as well as assistant and associate programs; this could have influenced the results, as some departments practice differently than others. Additionally, the study was conducted during the beginning of the summer and during the COVID-19 pandemic, when several directors were on leave and others were busy finalizing academic requirements for physicians-in-training preparing to graduate or joining the program.

\section{Conclusions}

High EQ skills are associated with low burnout rates. The positive impact of EQ skills is not only limited to elevating leaders' well-being and increasing retention; but also improves the well-being and productivity of the team, and contributes to maintaining effective communication and a supportive culture. Regular EQ skills sessions should be included in the process of preparing program directors for their roles. This study calls for further EQ investigation using qualitative methods. It is also a call for the ACGME to investigate the responsibilities assigned to residency and fellowship program directors that could be contributing to experience burnout. Further, given the undeniable impact that the COVID-19 pandemic has had on medical educational [cite] and, by extension, program leaders. Future research should aim to evaluate the impact that the changes that occurred due to the COVID-19 pandemic may have on these associations moving forward.

\begin{abstract}
Abbreviations
ACGME: Accreditation Council for Graduate Medical Education; CBI: Copenhagen Burnout Inventory; CL: Confidence Limits; EM: Emotionality; EQ: Emotional intelligence; IRB: Institutional Review Board; N: Number; PCC: Pearson Correlation Coefficient; SC: Self-control; SCC: Spearman Correlation Coefficients; SD: Standard Deviation; SOC: Sociability; TEIQue-SF: Trait Emotional Intelligence Questionnaire - Short Form; WB: Well-being; WHO: World Health Organization.
\end{abstract}

\section{Acknowledgments}

The authors would like to thank Dr. Beth Herman, Penn State director of graduate medical education, for her support of this research; program directors and associates for finding the time to participate and provide such valuable input; and Dr. Yendelela Cuffee, assistant professor, epidemiology, University of Delaware, for her constructive feedbacks.

\section{Disclosures}

None.

\section{Authors' contributions}

Conceptualization: Eiman Khesroh; Methodology: Eiman Khesroh, Melissa Butt, Andrea Rigby, Douglas Leslie, and Betsy Aumiller; Formal Analysis and Investigation: Eiman Khesroh, Melissa Butt; Writing - Original Draft: Eiman Khesroh; Table and Figure Preparation: Eiman Khesroh and Melissa Butt; Writing - Critical Review and Editing: Eiman Khesroh, Melissa Butt, Andrea Rigby, Douglas Leslie, Annahieta Kalantari, Sarah Bronson, and Betsy Aumiller. The author(s) read and approved the final manuscript.

\section{Funding}

The use of REDCap was supported by The Penn State Clinical \& Translational Research Institute, Pennsylvania State University CTSA, NIH/NCATS Grant Number UL1 TR002014. Dr. Melissa Butt was supported by the Health Resources and Services Administration (HRSA) of the U.S. Department of Health and Human Services (HHS) as part of an award totaling $\$ 381,932$ with $14 \%$ financed with non-governmental sources. The contents are those of the author(s) and do not necessarily represent the official views of, nor an endorsement, by HRSA, HHS or the U.S. Government. For more information, please visit HRSA.gov.

\section{Availability of data and materials}

The datasets generated and/or analyzed during the current study are not publicly available due to ethical and regulatory restrictions.

\section{Declarations}

Ethics approval and consent to participate

Approval: This study has been reviewed and approved as exempt by the Penn State Institutional Review Board: STUDY00017242.

Accordance: The methods used in this study were carried in accordance with the guidelines and regulations of the Declaration of Helsinki. Participation was voluntary and participants were kept confidential during data collection with limited number of identifiers and limited number of individuals with access to the data.

Informed consent: Informed consent was obtained from all participants via reviewing the summary explanation of research and agreeing to continue on to the survey.

\section{Consent for publication}

Not Applicable.

\section{Competing interests}

The authors declare that they have no competing interests.

\section{Author details}

${ }^{1}$ Department of Public Health Sciences, Penn State College of Medicine, Hershey, PA, USA. ${ }^{2}$ Department of Family and Community Medicine, Penn State College of Medicine, Hershey, PA, USA. ${ }^{3}$ Department of Emergency Medicine, Penn State Milton S. Hershey Medical Center, Hershey, PA, USA. ${ }^{4}$ Department of Cellular and Molecular Physiology, Penn State College of Medicine, Hershey, PA, USA. ${ }^{5}$ Department of Surgery - Division of Minimally Invasive Surgery,

Penn State Milton S. Hershey Medical Center, Hershey, PA, USA.

Received: 29 October 2021 Accepted: 14 February 2022

Published online: 25 February 2022

\section{References}

1. Burn-out an "occupational phenomenon": International Classification of Diseases. https://www.who.int/news/item/28-05-2019-burn-outan-occupational-phenomenon-international-classification-of-diseases. Accessed 20 Sept 2021 
2. Shanafelt TD, Hasan O, Dyrbye LN, Sinsky C, Satele D, Sloan J, et al. Changes in burnout and satisfaction with work-life balance in physicians and the general US working population between 2011 and 2014. Mayo Clin Proc. 2015;90(12):1600-13.

3. Dewa CS, Loong D, Bonato S, Trojanowski L. The relationship between physician burnout and quality of healthcare in terms of safety and acceptability: a systematic review. BMJ. 2017:7(6):e015141.

4. Patel RS, Bachu R, Adikey A, Malik M, Shah M. Factors related to physician burnout and its consequences: a review. Behav Sci (Basel, Switzerland). 2018;8(11):98.

5. Hamidi MSBB, Sandborg C, et al. Estimating institutional physician turnover attributable to self-reported burnout and associated financial burden: a case study. BMC Health Serv Res. 2018;18(1):851.

6. Skipper GECM, Dupont RL. Anesthesiologists with substance use disorders: a 5-year outcome study from 16 state physician health programs. Anesth Analg. 2009;109(3):891-6.

7. Deligkaris P, Panagopoulou E, Montgomery AJ, Masoura E. Job burnout and cognitive functioning: a systematic review. Work \& stress. Work Stress. 2014;28(2):107-23.

8. Koutsimani P, Montgomery A, Masoura E, Panagopoulou E. Burnout and Cognitive Performance. Int J Environ Res Public Health. 2021;18(4):2145.

9. Goleman D, Boyatzis RE. Emotional Intelligence Has 12 Elements. Which one Do you Need to Work On?. Harv Bus Rev. 2017. [https://hbr.org/2017/ 02/emotional-intelligence-has-12-elements-which-do-you-need-towork-on]. Accessed 14 Sept 2021.

10. Goleman D. Emotional intelligence: why it can matter more than IQ. New York: Bantam Books; 1995.

11. Boyatzis RE, McKee A. Primal Leadership: The Hidden Driver of Great Performance. Harv Bus Rev. 2001. [https://hbr.org/2001/12/primal-leade rship-the-hidden-driver-of-great-performance]. Accessed 14 Sept 2021.

12. Shanafelt T, Swensen S. Leadership and physician burnout: using the annual review to reduce burnout and promote engagement. Am J Med Qual. 2017;32(5):563-5.

13. Shanafelt TD, Noseworthy $\mathrm{JH}$. Executive leadership and physician well-being: nine organizational strategies to promote engagement and reduce burnout. Mayo Clin Proc. 2017;92(1):129-46.

14. Satterfield J, Swenson S, Rabow M. Emotional intelligence in internal medicine residents: educational implications for clinical performance and burnout. Ann Behav Sci Med Educ. 2009;14(2):65-8.

15. Cofer KD, Hollis RH, Goss L, Morris MS, Porterfield JR, Chu DI. Burnout is associated with emotional intelligence but not traditional job performance measurements in surgical residents. J Surg Educ. 2018;75(5):1171-9.

16. O'Connor AB, Halvorsen AJ, Cmar JM, Finn KM, Fletcher KE, Kearns $L$, et al. Internal medicine residency program director burnout and program director turnover: results of a national survey. Am J Med. 2019;132(2):252-61.

17. Harris PATR, Thielke R, Payne J, Gonzalez N, Conde JG. Research electronic data capture (REDCap)--a metadata-driven methodology and workflow process for providing translational research informatics support. J Biomed Inform. 2009;42(2):377-81.

18. Sestili C, Scalingi S, Cianfanelli S, Mannocci A, Del Cimmuto A, De Sio S, Chiarini M, Di Muzio M, Villari P, De Giusti M, La Torre G. Reliability and Use of Copenhagen Burnout Inventory in Italian Sample of University Professors. Int J Environ Res Public Health. 2018;15(8):1708.

19. Creedy DK, Sidebotham M, Gamble J, Pallant J, Fenwick J. Prevalence of burnout, depression, anxiety and stress in Australian midwives: a crosssectional survey. BMC Pregnancy Childbirth. 2017;17(1):13.

20. Robinson E, Hull L, Petrides KV. Big Five model and trait emotional intelligence in camouflaging behaviours in autism. Pers Individ Differ. 2020;152:109565

21. Petrides KV. Psychometric properties of the trait emotional intelligence questionnaire. In: Stough C, Saklofske DH, Parker JD, editors. Advances in the assessment of emotional intelligence. New York: Springer; 2009.

22. Hall AK, Nousiainen MT, Campisi P, Dagnone JD, Frank JR, Kroeker KI, Brzezina S, Purdy E, Oswald A. Training disrupted: Practical tips for supporting competency-based medical education during the COVID-19 pandemic. Medical Teacher. 2020;42(7):756-61.

23. Kaul V, Gallo de Moraes A, Khateeb D, Greenstein Y, Winter G, Chae J, Stewart NH, Qadir N, Dangayach NS. Medical Education During the COVID-19 Pandemic. Chest. 2021;159(5):1949-60.
24. Common Program Requirements (Residency). https://www.acgme. org/Portals/0/PFAssets/ProgramRequirements/CPRResidency2019. pdf. Accessed 20 Sept 2021

25. Fernald DHC, Brown SR. Why family medicine program directors leave their position. Fam Med. 2021;53(5):347-54.

26. Greenberger SM, Finnell JT 2nd, Chang BP, Garg N, Quinn SM, Bird S, et al. Changes to the ACGME common program requirements and their potential impact on emergency medicine Core Faculty protected time. AEM education and training. 2020;4(3):244-53.

27. Weisinger $\mathrm{H}$. Emotional intelligence at work New York. United States: John Wiley \& Sons Inc; 1998

28. Salovey PMJ. Emotional intelligence. Imagin Cogn Pers. 1990;9(3):185-211.

\section{Publisher's Note}

Springer Nature remains neutral with regard to jurisdictional claims in published maps and institutional affiliations.
Ready to submit your research? Choose BMC and benefit from:

- fast, convenient online submission

- thorough peer review by experienced researchers in your field

- rapid publication on acceptance

- support for research data, including large and complex data types

- gold Open Access which fosters wider collaboration and increased citations

- maximum visibility for your research: over $100 \mathrm{M}$ website views per year

At BMC, research is always in progress.

Learn more biomedcentral.com/submissions 